\title{
Expected Budget Impact and Health Outcomes of Expanded Use of Vagus Nerve Stimulation Therapy for Drug-Resistant Epilepsy
}

\author{
Molly F. Purser · Deirdre M. Mladsi · Alan Beckman · Francesca Barion • \\ John Forsey
}

Received: May 15, 2018 / Published online: August 24, 2018

(C) The Author(s) 2018, corrected publication September/2018

\section{ABSTRACT}

Introduction: The objective was to estimate, from the perspective of a managed care organization in the United States, the budget impact and effect on health outcomes of expanded use of vagus nerve stimulation [VNS (VNS Therapy $\left.{ }^{\circledR}\right)$ ] among patients aged $\geq 12$ years with drug-resistant epilepsy (DRE) with partial-onset seizures.

Methods: An Excel model was developed to compare the costs of continued anti-epileptic drug (AED) treatment with the costs of VNS plus AED treatment. The number of people eligible for VNS was estimated using published prevalence data and an estimate of the percentage of eligible patients currently without VNS. Costs

Enhanced digital content To view enhanced digital content for this article go to https://doi.org/10.6084/ m9.figshare.6955193.

The original version of this article was revised due to retrospective Open Access order.

M. F. Purser $(\bowtie)$ - D. M. Mladsi

RTI Health Solutions, Research Triangle Park, NC,

USA

e-mail: mpurser@rti.org

A. Beckman

LivaNova USA, Inc., Houston, TX, USA

F. Barion · J. Forsey

LivaNova PLC, London, UK included VNS device, placement, programming, and battery changes; adverse events associated with VNS (cough, voice alteration, device removal resulting from surgical site infection); AEDs; and seizure-related costs affected by seizure frequency, which affects resource utilization (i.e., hospitalizations, emergency department visits, neurologist visits). To estimate the potential savings with VNS due to a reduction in seizure frequency, the budget impact model uses the results of an underlying Markov model to estimate seizure-related costs by seizure frequency. Transitions occurred among four health states, defined by number of seizures per month (i.e., seizure-free, $\leq 1,>1$ to $<10, \geq 10$ ) on a 3 -month cycle based on published clinical trials and registry data.

Results: VNS resulted in an estimated net cost savings, on average, over 5 years, due to the expected reduction in seizure frequency. The initial cost of the VNS device, placement, and programming was estimated to be offset 1.7 years after VNS device placement. Reductions in hospitalizations were the main contributor to the cost savings with VNS.

Conclusions: VNS is a proven intervention that offers a long-term solution for patients with DRE by reducing seizure frequency, which leads to lower resource utilization and lower costs.

Funding: LivaNova PLC.

Keywords: Cost model; Drug-resistant epilepsy; Economic evaluation; Epilepsy, 
Neurology; Vagus nerve stimulation; VNS Therapy

\section{INTRODUCTION}

Approximately one-third of patients with epilepsy have drug-resistant epilepsy (DRE) [1]. Patients with DRE require more health care resources [e.g., hospitalizations, emergency department (ED) visits] and are more costly to manage than patients with epilepsy treated successfully with anti-epileptic drugs (AEDs) [2]. Treatment options for patients with DRE include ketogenic diet, resective brain surgery to remove the focal area responsible for the epileptic seizures, severing the corpus callosum that connects the two hemispheres of the brain, responsive neurostimulation, and vagus nerve stimulation (VNS; VNSTherapy ${ }^{\circledR}$; LivaNova; Houston, Texas]) [3, 4]. VNS is reimbursed in over 50 countries including France [5] and the UK [6]. VNS was approved by the Food and Drug Administration (FDA) in 1997 as an adjunctive treatment for patients 12 years or older with partial-onset seizures that are not responsive to AEDs [7]. In 2017, the FDA expanded the indication to include patients as young as 4 years old [8]. Over 100,000 patients with DRE have been managed globally with VNS since 1989 [9]. A recent Cochrane Review found VNS to be "an effective and well-tolerated treatment" (p. 2) based on evidence from five clinical trials [10]. In addition, the American Academy of Neurology found VNS to be a safe and effective treatment for epilepsy [11]. Despite the long-term proven effectiveness of VNS [12], the time to initial implant occurs approximately 20 years after initial diagnosis (Janszky et al. [13]; Cyberonics, data on file, 1997) and after an average of 7 AEDs have been tried [14]. VNS has been shown to reduce health care resource use $[15,16]$ and costs [16] compared with AEDs alone.

The objective of this research was to estimate, from the perspective of a United States (US) health care payer, the budget impact and population health outcomes that may be expected with expanded use of VNS among patients with DRE aged $\geq 12$ years with partialonset seizures.

\section{METHODS}

An Excel-based model was developed to compare the costs of continued AED treatment with the costs of VNS in addition to AED treatment in patients with DRE. This article is based on previously conducted studies and does not contain any studies with human participants or animals performed by any of the authors.

\section{Patient Population}

The number of eligible patients was calculated to be 1,536, based on an assumed 1-millionmember health plan, with $84 \%$ of the plan population being $\geq 12$ years of age [17], $0.94 \%$ having epilepsy [18], 57\% of those with epilepsy having partial-onset seizures [19] and 36\% of those with partial-onset seizures having DRE [1]. In addition, the analysis assumed that $95 \%$ of patients $\geq 12$ years old with partial-onset seizures who have DRE currently do not have VNS. Although DRE has been defined by the International League Against Epilepsy as "a failure of adequate trials of two tolerated and appropriately chosen and used AED schedules (whether as monotherapy or in combination) to achieve sustained seizure-freedom" [20; p. 1073], the duration of epilepsy for patients who undergo VNS device placement has been reported to be approximately 20 years (Cyberonics, data on file, 1997; Janszky et al. [13]), suggesting that the percentage of patients with DRE without VNS is high.

\section{Cost Inputs}

Model inputs include the costs associated with the VNS device, placement, programming, and battery changes; adverse events due to VNS (cough, voice alteration, device removal resulting from surgical site infection); and AEDs (Table 1); and seizure-related costs. All costs are presented in 2016 US dollars. 
Table 1 Model inputs: costs (per person) for VNS (device- and adverse event-related) and AEDs, with and without VNS

\begin{tabular}{|c|c|c|c|}
\hline Cost component & $\begin{array}{l}\text { Without } \\
\text { VNS }\end{array}$ & $\begin{array}{l}\text { With } \\
\text { VNS }\end{array}$ & Sources/assumptions \\
\hline \multicolumn{4}{|l|}{ VNS device-related costs } \\
\hline $\begin{array}{l}\text { VNS system device (generator, } \\
\text { lead, tunneler) }\end{array}$ & NA & $\$ 36,239$ & $\begin{array}{l}\text { LivaNova Price List-US (LivaNova, data on file, 2017). } \\
\text { Assumes each patient receives one implant }\end{array}$ \\
\hline $\begin{array}{l}\text { Procedure for full system } \\
\text { placement }\end{array}$ & NA & $\$ 2661$ & $\begin{array}{l}\text { Estimate based on } 1.5 \mathrm{~h} \text { of surgical time (LivaNova, data on } \\
\text { file 2017) }\end{array}$ \\
\hline Neurologist visits for programming & NA & $\$ 319$ & $\begin{array}{l}\text { Based on national average cost for neurologist visit for } \\
\text { programming (cyberonics VNS therapy hospital codes; } \\
\text { Cyberonics, data on file, 2016), assuming three neurologist } \\
\text { visits }\end{array}$ \\
\hline $\begin{array}{l}\text { Battery (generator) replacement } \\
\text { (per person per year) }\end{array}$ & NA & $\$ 2178$ & $\begin{array}{l}\text { Sum of battery cost (LivaNova Price List-US; LivaNova, data } \\
\text { on file, 2017), procedure cost ( } 30 \text { min of surgical time; } \\
\text { LivaNova, data on file, 2017), and neurologist visit for } \\
\text { reprogramming (Cyberonics VNS therapy hospital codes; } \\
\text { Cyberonics, data on file, 2016). Assumes 50\% of patients } \\
\text { will have a battery replacement at } 7 \text { years [31] }\end{array}$ \\
\hline \multicolumn{4}{|l|}{ VNS adverse events costs ${ }^{\mathrm{a}}$} \\
\hline $\begin{array}{l}\text { Neurologist visit for cough (one- } \\
\text { time cost) }\end{array}$ & $\$ 0.00$ & $\$ 40$ & Incidence of $37.5 \% \times$ unit cost of $\$ 106$ \\
\hline $\begin{array}{l}\text { Neurologist visit for voice } \\
\text { alteration (one-time cost) }\end{array}$ & $\$ 0.00$ & $\$ 42$ & Incidence of $39.7 \% \times$ unit cost of $\$ 106$ \\
\hline $\begin{array}{l}\text { Surgical site infection, which } \\
\text { results in device removal (one- } \\
\text { time cost) }\end{array}$ & NA & $\$ 95$ & Incidence of $2.8 \% \times$ unit cost of $\$ 3397$ \\
\hline \multicolumn{4}{|l|}{ AED costs } \\
\hline AEDs (cost per year) & $\$ 6502$ & $\$ 6502$ & $\begin{array}{l}\text { Average cost calculated as the average daily cost of lacosamide, } \\
\text { lamotrigine, topiramate, oxcarbazepine, levetiracetam, } \\
\text { carbamazepine, tiagabine [32], and assuming that } 2 \text { AEDs } \\
\text { are used per day. No change in the number of AEDs is } \\
\text { expected with VNS [29] }\end{array}$ \\
\hline
\end{tabular}

$A E D$ anti-epileptic drug, $N A$ not applicable, $U S$ United States, $V N S$ vagus nerve stimulation (VNSTherapy ${ }^{\circledR}$ )

a Cough and voice alteration incidence rates for VNS are calculated as the weighted average of rates reported in clinical trials E03 (Cyberonics, data on file, 1997) and E05 (Cyberonics, data on file, 1997). The incidence of surgical site infection and subsequent device removal is the average number of VNS device removals due to surgical site infection based on the manufacturer's safety database (LivaNova, data on file, 2016). Surgical site infection is assumed to occur after implantation and to result in removal of the device (LivaNova, data on file, 2015). No adverse events are included for patients not receiving VNS. Cost of neurologist visit based on national average (Cyberonics VNS therapy hospital codes; Cyberonics, data on file, 2016). Patients with surgical site infection are assumed to incur the cost of VNS device implantation and VNS device removal (at a cost of \$3397) and not to receive the benefit from VNS. The cost of VNS device removal is the US national average for device removal (Cyberonics VNS therapy hospital codes; Cyberonics, data on file, 2016) 
Table 2 Model inputs, seizure-related costs: annual resource utilization and costs (per person), by resource and seizure frequency

\begin{tabular}{|c|c|c|c|c|}
\hline \multirow[t]{2}{*}{ Resource (unit $\operatorname{cost}^{\mathrm{a}}$ ) } & \multicolumn{4}{|c|}{ Number of seizures per month annual cost } \\
\hline & 0 (seizure-free) & $\leq 1$ & $>1$ to $<10$ & $\geq 10$ \\
\hline \multirow[t]{2}{*}{ Hospitalization $^{\mathrm{b}}(\$ 12,360)$} & 0.00 & 0.48 & 0.96 & 4.8 \\
\hline & $\$ 0$ & $\$ 5933$ & $\$ 11,866$ & $\$ 59,330$ \\
\hline \multirow[t]{2}{*}{$\mathrm{ED}_{\text {visit }^{\mathrm{c}}}(\$ 1079)$} & 0.00 & 0.42 & 0.85 & 3.57 \\
\hline & $\$ 0$ & $\$ 453$ & $\$ 917$ & $\$ 3,852$ \\
\hline \multirow[t]{2}{*}{ Neurologist visit $^{\mathrm{d}}(\$ 106)$} & 16.62 & 17.37 & 18.12 & 22.54 \\
\hline & $\$ 1769$ & $\$ 1849$ & $\$ 1929$ & $\$ 2399$ \\
\hline Total cost & $\$ 1769$ & $\$ 8235$ & $\$ 14,712$ & $\$ 65,581$ \\
\hline
\end{tabular}

$A E D$ anti-epileptic drug, $E D$ emergency department, US United States, USD United States dollars, VNS vagus nerve stimulation (VNSTherapy ${ }^{\circledR}$ )

${ }^{a}$ Hospitalization costs [33], inflated to 2016 USD [34]; ED visit costs [35], inflated to 2016 USD [34]; neurologist visit cost based on national average (Cyberonics VNSTherapy, hospital codes; Cyberonics, data on file, 2016)

b Assumption of no hospitalizations for the seizure-free category is based on a study by Kristian et al. [36]. The annual number of hospitalizations for the $\leq 1$ seizure per month category is estimated as the midpoint between the annual number of hospitalizations for the seizure-free category and the $>1$ to $<10$ seizures per month category. The annual number of hospitalizations for the $>1$ to $<10$ seizures per month category is based on a study by Bernstein and Hess [15]. The annual number of hospitalizations for the $\geq 10$ seizures per month category is based on a study by Kristian et al. [36], which estimated the number of hospitalizations for patients responding and not responding to an AED, where response was measured in clinical trials where the baseline seizure frequency was 26.7 per month and where responders had an average seizure frequency of 6.7 per month. The resulting number of hospitalizations for nonresponders was 5 times higher than for responders. For the annual number of hospitalizations for the $\geq 10$ seizures per month category, the model assumes it is 5 times that of the $>1$ to $<10$ seizures per month category

${ }^{c}$ Numbers of visits for the seizure-free and $\geq 10$ seizures per month categories are from Kristian et al. [36]. Number of ED visits for the $>1$ to $<10$ seizures per month category is calculated as the sum of ED visits for the first four quarters postVNS initiation reported in Berstein et al. [15]. Number of ED visits for the $\leq 1$ seizure per month category was estimated as the midpoint between the annual number of ED visits for the seizure-free category $(0)$ and annual number of ED visits for the $>1$ to $<10$ seizures per month category

${ }^{\mathrm{d}}$ Number of neurologist outpatient visits for the seizure-free category was estimated to be 1.09 times less than responders ( $\geq 50 \%$ reduction in seizure frequency) based on Kristian et al. [36]; therefore, the number of outpatient visits for the seizure-free category is calculated as $18.12 / 1.09=16.62$, assuming response is achieved with $>1$ to $<10$ seizures per month. Number of neurologist visits for the $>1$ to $<10$ seizures per month category is calculated as the sum of the neurologist visits for the first four quarters post-VNS. For the $\geq 10$ seizures per month category, the number of neurologist visits is estimated by applying the relative increase in the number of outpatient visits reported by Kristian et al. [36] for nonresponders versus responders to the number for the $>1$ to $<10$ seizures per month category. The number of visits for the $\leq 1$ seizure per month category is estimated as the midpoint between the numbers of visits for the seizure-free and $>1$ to $<10$ seizures per month categories

\section{Seizure-Related Costs}

Seizure-related costs for hospitalizations, ED visits, and neurologist visits are calculated by estimating expected levels of seizure frequency for patients without VNS and for patients with
VNS using a previously published model structure [21]. The health states, as described in a cost-utility analysis of an AED [22], are based on monthly seizure frequency, and are seizurefree, $\leq 1$ seizure per month, $>1$ to $<10$ seizures per month, and $\geq 10$ seizures per month. 
All patients begin in the health state " $\geq 10$ seizures per month" based on the reported baseline weighted median number of seizures per month (16.3) in the VNS clinical trial E05 (Cyberonics, data on file, 1997). The allocation of patients by health state at 3 months was based on a post hoc analysis of the clinical trial data [21]. From that point, every 3 months to month 24 , VNS patients transition to a health state determined by results from a systematic review of the literature and the VNS Therapy Patient Outcomes Registry [12]. Based on Englot et al. [12], the model assumes that no further changes in seizure frequency occur beyond month 24 . Patients in the model that receive AEDs alone do not improve over time. A randomized study of patients receiving AEDs alone or VNS plus AEDs found, at 12 months, no change in seizure frequency for patients that received AEDs alone [23]. The model includes seizure-related resource utilization estimates for hospitalizations, ED visits, and neurologist visits by seizure frequency, which are multiplied by the corresponding unit costs to calculate the annual resource costs by seizure frequency (Table 2). The resulting seizure-related costs without and with VNS are shown in Table 3.

\section{RESULTS}

In a modeled analysis of VNS placed in eligible patients at year 1, VNS resulted in an estimated net cost savings due to expected reductions in seizure frequency beginning the second year after VNS device placement (Fig. 1; Table 4). The initial cost of the VNS device, placement, and programming was offset in 1.7 years after device placement (Fig. 2). On average, VNS resulted in an estimated net cost savings of $\$ 77,480$ per patient over 5 years, which is a $21.5 \%$ reduction in costs compared with AEDs alone. Patients with VNS had an estimated reduction in costs associated with seizure frequency of $\$ 127,554$ per patient over 5 years compared with patients with AEDs alone. Seizure-related hospitalizations were the main cost driver, resulting in an estimated cost reduction of $\$ 118,925$ per patient over 5 years for patients with VNS compared with AEDs alone (Fig. 3). A one-way sensitivity analysis was conducted, which varied by $\pm 20 \%$ the eligible patient population, VNS costs, adverse event costs, AED costs, and individual per-person resource costs per year with and without VNS. Results were most sensitive to per-person hospitalization cost per year with and without VNS in the third to fifth years after VNS device placement; however, VNS remained cost saving over 5 years (Fig. 4).

The International Society for Pharmacoeconomics and Outcomes Research budget impact analysis good practices task force recommends uncertainty be explored through scenario analyses rather than through standard approaches such as probabilistic sensitivity analysis [24]. Two scenario analyses were conducted. The first scenario increased the number of patients who are seizure-free at 24 months from 8 to $15.4 \%$. This scenario is supported by Elliott et al. [27], who reported that $15.4 \%$ of patients were seizure-free for at least 2 years prior to the last follow-up visit in a study of 65 consecutive patients with at least 10 years of follow-up. This scenario resulted in a cost reduction over 5 years of $22.5 \%$ with VNS compared with AEDs alone compared with the cost reduction of $21.5 \%$

Table 3 Calculated model inputs: seizure-related costs (per person) without and with VNS therapy, by resource and year

\begin{tabular}{|c|c|c|c|c|c|c|}
\hline & \multicolumn{2}{|l|}{ 1st year } & \multicolumn{2}{|l|}{ 2nd year } & \multicolumn{2}{|l|}{3 rd-5th year } \\
\hline & Without VNS & With VNS & Without VNS & With VNS & Without VNS & With VNS \\
\hline Hospitalization & $\$ 59,330$ & $\$ 38,737$ & $\$ 59,330$ & $\$ 34,954$ & $\$ 59,330$ & $\$ 33,536$ \\
\hline ED visits & $\$ 3852$ & $\$ 2571$ & $\$ 3852$ & $\$ 2329$ & $\$ 3852$ & $\$ 2238$ \\
\hline Neurologist visits & $\$ 2399$ & $\$ 2193$ & $\$ 2399$ & $\$ 2154$ & $\$ 2399$ & $\$ 2139$ \\
\hline Total & $\$ 65,581$ & $\$ 43,501$ & $\$ 65,581$ & $\$ 39,437$ & $\$ 65,581$ & $\$ 37,913$ \\
\hline
\end{tabular}

VNS vagus nerve stimulation (VNS Therapy ${ }^{\circledR}$ ) 


\section{Without VNS Therapy}
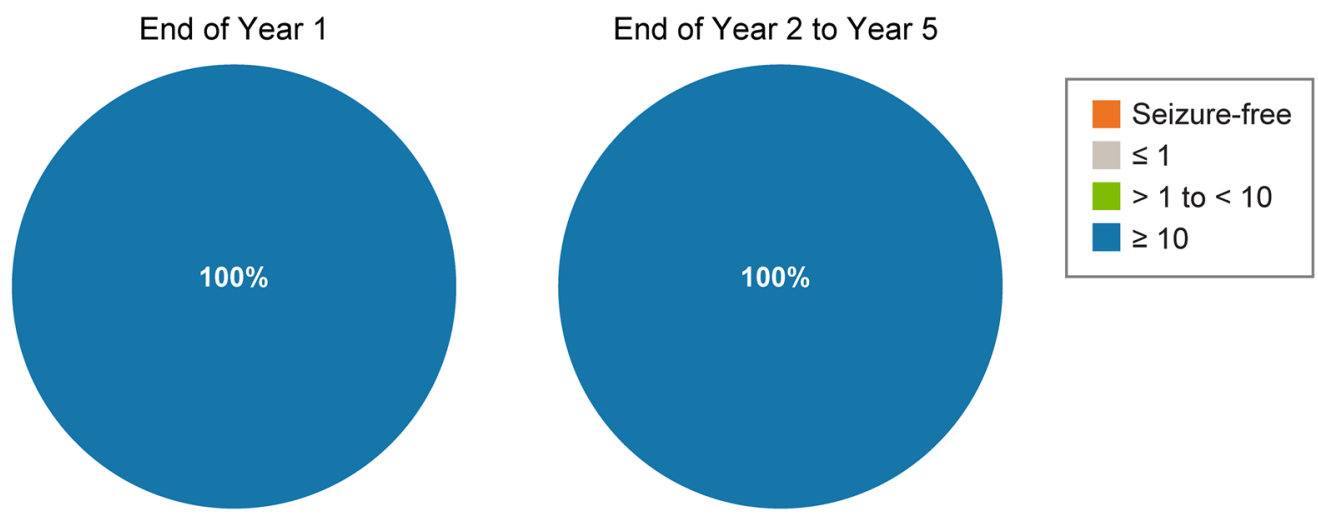

\section{With VNS Therapy}
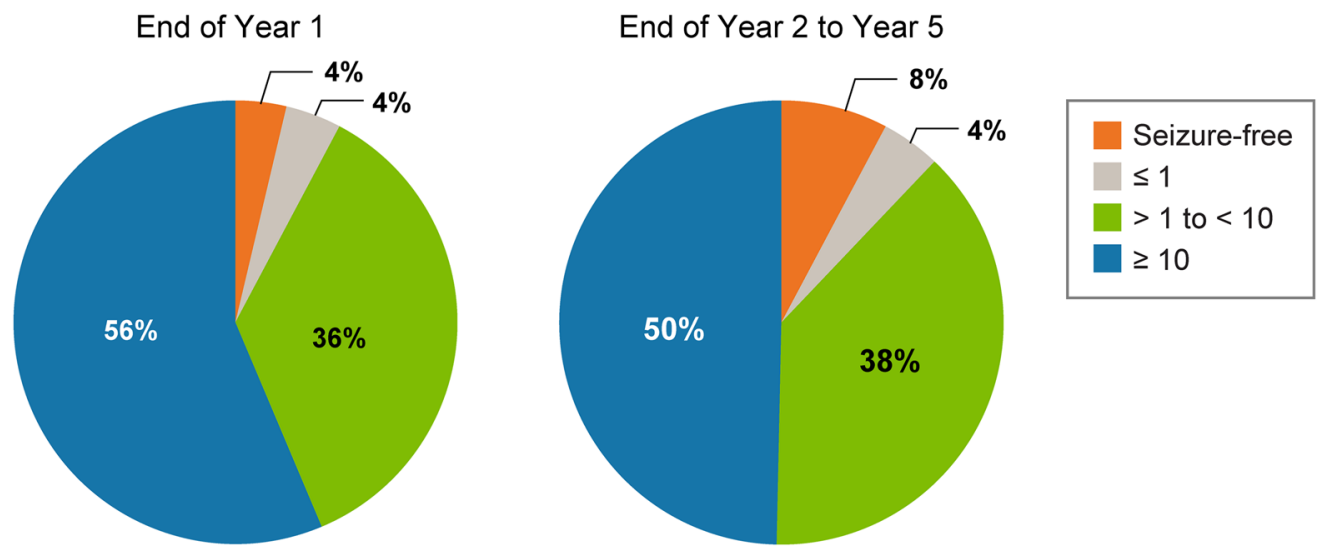

Fig. 1 Percentage of patients by number of seizures per month. $S F$ seizure-free, $V N S$ vagus nerve stimulation From Purser et al. [37]

Table 4 Results: total organization budget impact, by year

\begin{tabular}{lllll}
\hline & 1st year & 2nd year & 3rd-5th years (per year) & Total years 1-5 \\
\hline Cost without VNS & $\$ 110,709,545$ & $\$ 110,709,545$ & $\$ 110,709,545$ & $\$ 553,547,724$ \\
Cost with VNS & $\$ 141,644,874$ & $\$ 74,932,599$ & $\$ 72,657,493$ & $\$ 434,549,953$ \\
Budget impact & $\$ 30,935,329$ & $(\$ 35,776,946)$ & $(\$ 38,052,052)$ & $(\$ 118,997,771)$ \\
Relative difference & $27.94 \%$ & $-32.32 \%$ & $-34.37 \%$ & $-21.5 \%$ \\
\hline
\end{tabular}

$V N S$ vagus nerve stimulation (VNS Therapy ${ }^{\circledR}$ )

observed in the base case analysis. A second scenario analysis was conducted that assumed the percentage of patients in the $\geq 10$ seizures per month category at 3 months who moved to having $<10$ seizures per month at 24 months was $42 \%$ rather than the base case assumption of $20 \%$. This change results in $63 \%$ of patients having $<10$ seizures per month at 24 months. This scenario is supported by a study by Englot et al. [12], who reported that $63 \%$ of patients 


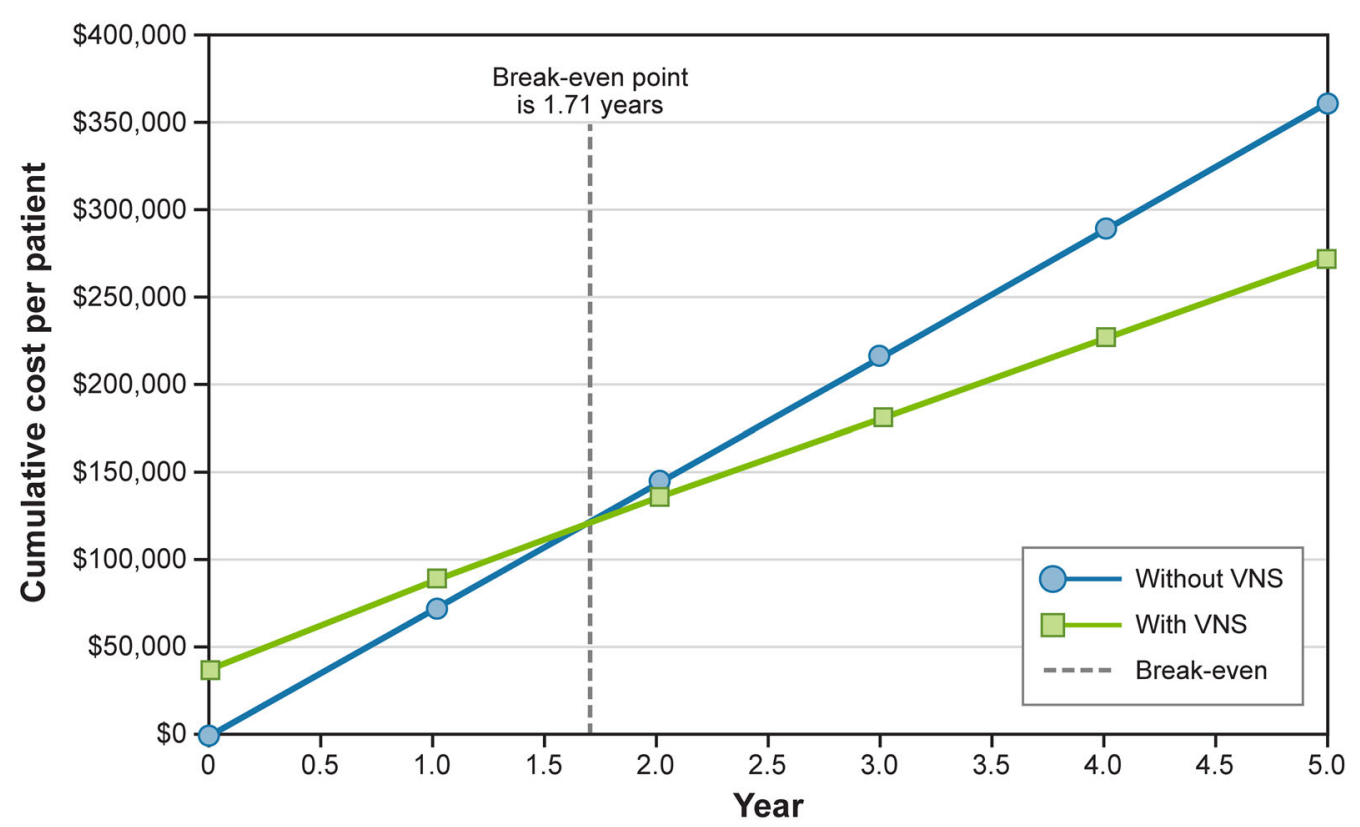

Fig. 2 Cumulative costs for patients without and with vns with break-even analysis. VNS vagus nerve stimulation From Purser et al. [37]

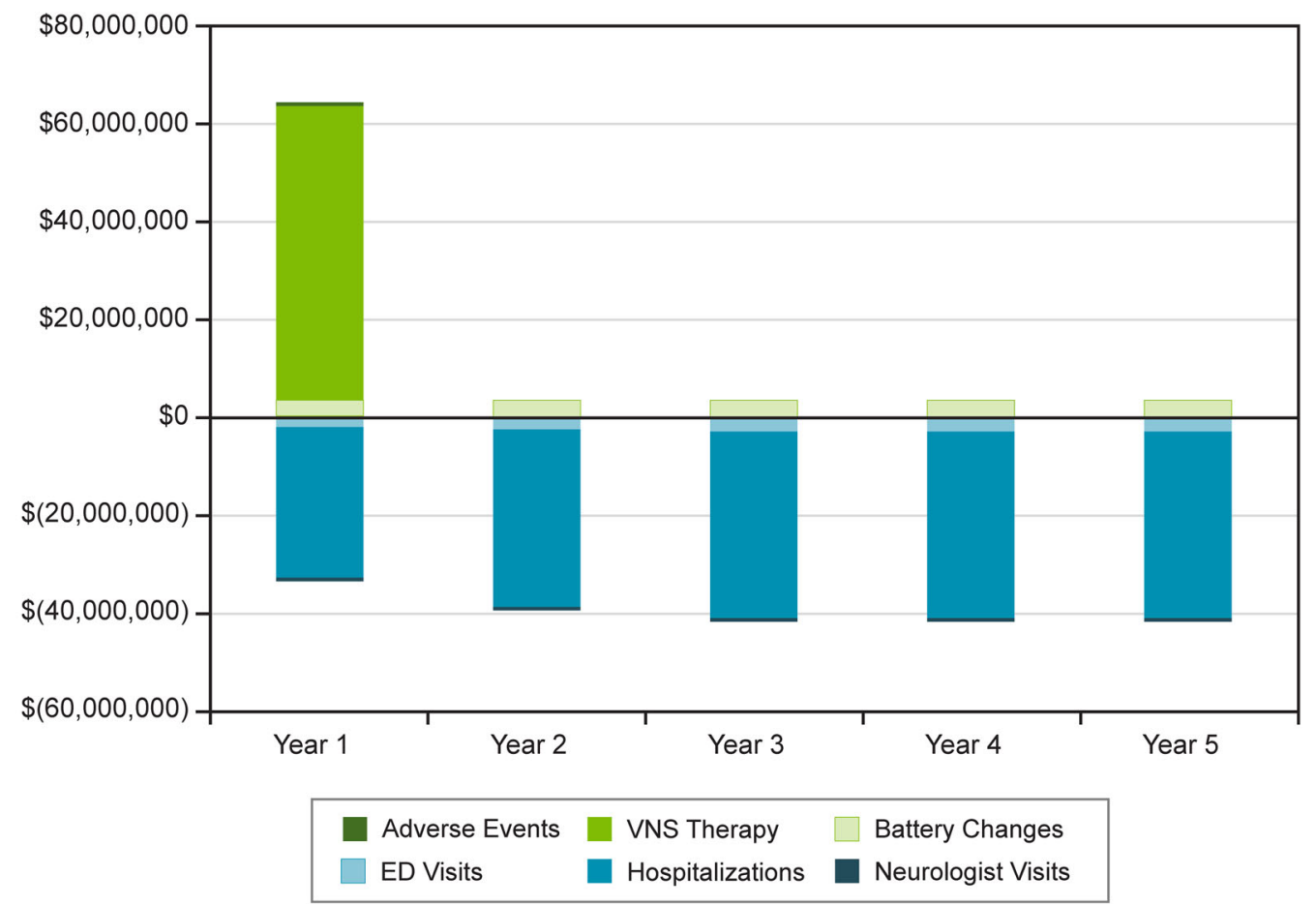

Fig. 3 Total plan budget impact by cost category by year. $A E D$ anti-epileptic drug, $E D$ emergency department, $V N S$ vagus nerve stimulation 


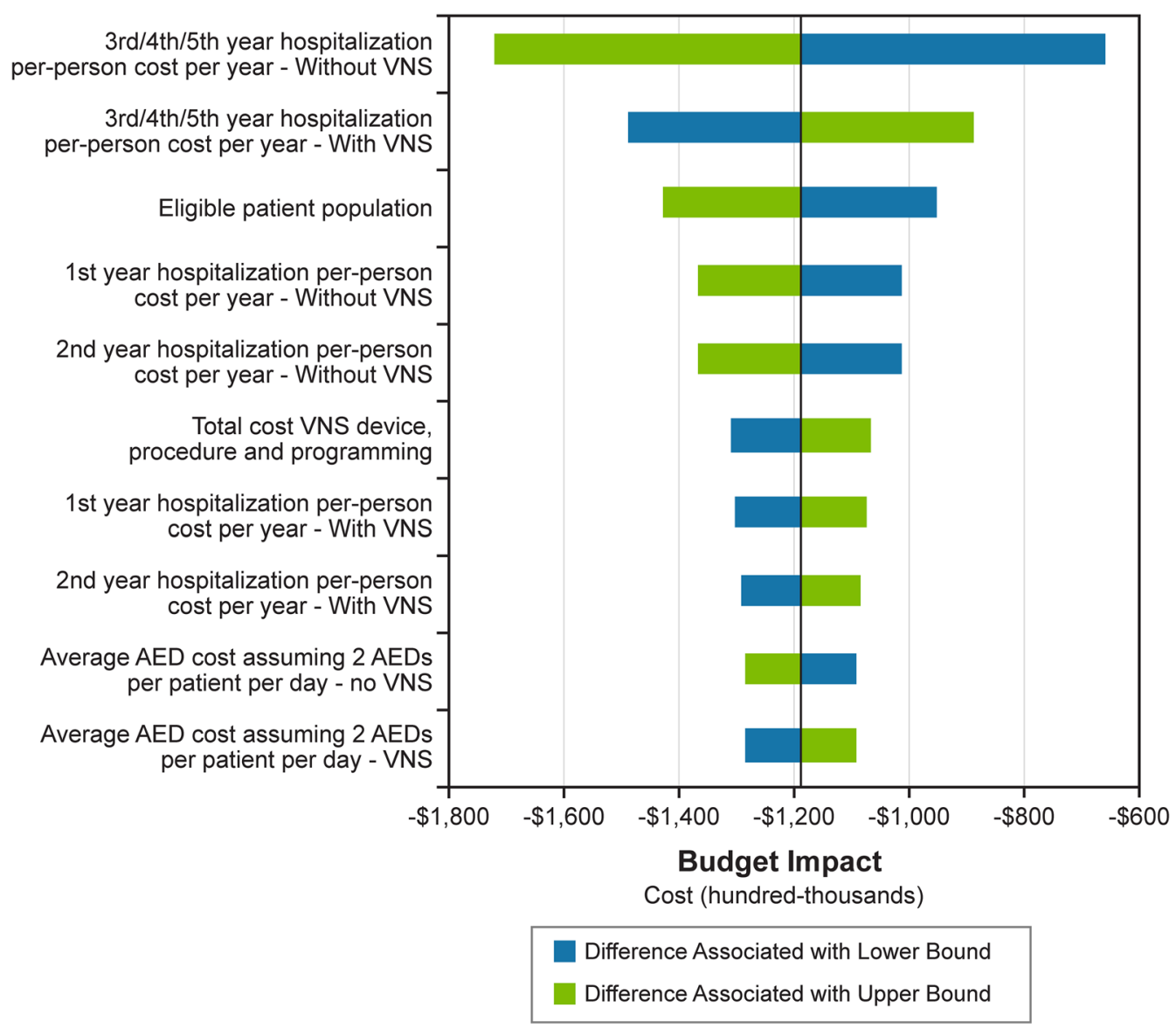

Fig. 4 One-way sensitivity analysis tornado diagram. $A E D$ anti-epileptic drug, $V N S$ vagus nerve stimulation

with VNS responded to treatment at 24-48 months, with response defined as a $\geq 50 \%$ reduction from baseline seizure frequency (which the current model assumes results in $<$ 10 seizures per month). This scenario resulted in a $28.9 \%$ cost reduction with VNS over 5 years, with a break-even point of 1.54 years.

\section{DISCUSSION}

The findings from this modeled economic analysis are consistent with previously published analyses. Helmers et al. [16] analyzed medical data from 1,655 patients and estimated total costs [inpatient, outpatient, ED, and drug (AED and non-AED)] for 6 months pre-VNS and up to 3 years post-VNS initiation. The study found that the cost of VNS (device, placement, and outpatient visits) was outweighed by the cost savings at about 1.5 years, which is similar to the finding from the current modeled analysis, which estimated complete cost offset to occur 1.7 years after device placement.

Helmers et al. [16] also reported the incidence for seizure-related hospitalizations before VNS and for the 3 years post-VNS initiation. The incidence for seizure-related hospitalizations was reduced by approximately $50 \%$ by the end of the second year post-VNS, and remained at this level for year 3. Bernstein et al. [15] analyzed Kaiser Permanente administrative data to evaluate the resource utilization of patients 1 year prior to VNS and up to 4 years post-VNS initiation. Bernstein et al. [15] also found that, at 4 years post-VNS initiation, hospitalization admissions were reduced by $70 \%$, ED visits were reduced by $99 \%$, and outpatient visits were reduced by $91 \%$ compared with the year prior to VNS implantation. 
In comparison, the current VNS modeled analysis estimated, by year 5 , reductions in hospitalizations by $40 \%$, ED visits by $39 \%$, and neurologist visits by $10 \%$ with VNS versus without VNS. The current analysis may be more conservative than previously published analyses because it does not include the potential reductions in resource use that patients with a baseline of 10 or more seizures per month may have with VNS. For example, a study by Boon et al. [25], which considered 15 patients before and after VNS initiation, reported that, even among patients who continued to have 10 or more seizures per month after VNS initiation, there was a decrease in hospital admissions and direct medical costs compared with before VNS initiation.

A recent study of 1,795 patients with epilepsy reported that, if patients were not seizurefree after the first AED, the second and third regimens provided a likelihood of 11.6 and $4.4 \%$, respectively, of providing seizure-freedom [26]. The study noted that, even with introduction over the past 2 decades of more than a dozen new AEDs with various mechanisms of action, the probability of obtaining seizurefreedom is dramatically reduced with each subsequent treatment [26]. However, patients have tried an average of 7 AEDs before VNS [14], suggesting that many patients may be able to benefit from earlier treatment with VNS.

The current model does not consider costs of removing the VNS device for reasons other than infection immediately following implantation. Elliot et al. [27] reviewed 436 consecutive patients that received VNS, and reported that $17 \%$ of patients had the device removed for reasons including lack of efficacy, planned magnetic resonance imaging, infection, AED success, and vocal cord paralysis; mean time to removal was 40.4 months from time of initial device placement. In addition, although VNS has been reported to reduce seizure severity [28], the model did not consider a reduction in costs and resource use due to a reduction in seizure severity.

The results of the current analysis, which used literature-based estimates, are consistent with and perhaps conservative compared with other published studies of the cost and resource use reductions that may be expected with VNS.
The US Food and Drug Administration (FDA) recently approved an age expansion to include patients as young as 4 years in the indication for VNS as an adjunctive therapy in reducing the frequency of seizures in patients with partialonset seizures that are refractory to anti-epileptic medications [8]. VNS in younger patients has been shown to be at least as effective as the currently modeled patient population ( $\geq 12$ years old) $[29,30]$; therefore, it would be expected that expanding the population to include patients aged 4 or more years would result in additional cost savings. Additional research is needed to determine the budget impact of expanding the population.

\section{CONCLUSIONS}

VNS is a proven intervention that offers a longterm solution for patients with DRE by reducing seizure frequency, which leads to lower resource utilization and lower costs.

\section{ACKNOWLEDGMENTS}

Funding. This study was conducted by RTI Health Solutions under the direction of LivaNova PLC and was funded by LivaNova PLC. Article processing charges were funded by LivaNova PLC. All authors had full access to all of the data in this study and take complete responsibility for the integrity of the data and accuracy of the data analysis.

Medical Writing, Editorial, and Other Assistance. The model structure was adapted from a model used in the LivaNova submission to the Medical Services Advisory Committee (application 1358.1) for vagus nerve stimulation for patients with refractory epilepsy [21]. The model was developed by Dominic Tilden and Koji Makino of THEMA Consulting Pty Ltd.

Authorship. All named authors meet the International Committee of Medical Journal Editors (ICMJE) criteria for authorship for this article, take responsibility for the integrity of 
the work as a whole, and have given their approval for this version to be published.

Disclosures. Alan Beckman is an employee of LivaNova PLC. Francesca Barion is an employee of LivaNova PLC. John Forsey is an employee of LivaNova PLC. Molly Purser is an employee of RTI Health Solutions. Deirdre Mladsi is an employee of RTI Health Solutions.

Compliance with Ethics Guidelines. This article is based on previously conducted studies and does not contain any studies with human participants or animals performed by any of the authors.

Data Availability. The datasets generated during and/or analyzed during the current study are available from the corresponding author on reasonable request.

Open Access. This article is distributed under the terms of the Creative Commons Attribution-NonCommercial 4.0 International License (http://creativecommons.org/licenses/ by-nc/4.0/), which permits any noncommercial use, distribution, and reproduction in any medium, provided you give appropriate credit to the original author(s) and the source, provide a link to the Creative Commons license, and indicate if changes were made.

\section{REFERENCES}

1. Kwan P, Brodie MJ. Early identification of refractory epilepsy. N Engl J Med. 2000;342(5):314-9.

2. Begley CE, Durgin TL. The direct cost of epilepsy in the United States: a systematic review of estimates. Epilepsia. 2015;56(9):1376-87.

3. Kwan P, Schachter SC, Brodie MJ. Drug-resistant epilepsy. N Engl J Med. 2011;365(10):919-26.

4. Ben-Menachem E. Neurostimulation-past, present, and beyond. Epilepsy Currents. 2012;12(5):188-91.

5. Haute Autorité de Santé. Stimulateur du nerf vague gauche NeuroCybernetic Prothesis (NCP) et électrode VNS bipolaire;2010.
6. National Institute for Health and Care Excellence [NICE]. The epilepsies: the diagnosis and management of the epilepsies in adults and children in primary and secondary care. NICE;2012. http:// www.nice.org.uk/guidance/cg137/chapter/1guidance\#vagus-nerve-stimulation-vns. Accessed 22 Feb 2017.

7. Food and Drug Administration. Summary of safety and effectiveness data (SSED), VNS Therapy, notice of approval, 16 July 1997. https://www.accessdata. fda.gov/scrIpts/cdrh/cfdocs/cfPMA/pma.cfm?id= 319777. Accessed 3 Apr 2018.

8. Food and Drug Admiration Summary of safety and effectiveness day (SSED), VNS Therapy, notice of approval;2017. https://www.accessdata.fda.gov/ cdrh_docs/pdf/p970003s207b.pdf. Accessed 3 Apr 2018.

9. Cyberonics. Cyberonics announces 100,000th patient implant of VNS Therapy ${ }^{\circledR}$. 2012. https:// www.prnewswire.com/news-releases/cyberonicsannounces-100000th-patient-implant-of-vnstherapy-184314661.html. Accessed 4 Apr 2018.

10. Panebianco M, Rigby A, Weston J, Marson AG et al. Vagus nerve stimulation for partial seizures. Cochrane Database Syst Rev;2015, 4:CD002896.

11. Fisher RS, Handforth A. Reassessment: vagus nerve stimulation for epilepsy: a report of the Therapeutics and Technology Assessment Subcommittee of the American Academy of Neurology. Neurology. 1999;53(4):666-9.

12. Englot DJ, Rolston JD, Wright CW, Hassnain $\mathrm{KH}$, Chang EF. Rates and predictors of seizure freedom with vagus nerve stimulation for intractable epilepsy. Neurosurgery. 2016;79(3):345-53.

13. Janszky J, Hoppe M, Behne F, Tuxhorn I, Pannek HW, Ebner A. Vagus nerve stimulation: predictors of seizure freedom. J Neurol Neurosurg Psychiatry. 2005;76(3):384-9.

14. Handforth A, DeGiorgio CM, Schachter SC, Uthman BM, Naritoku DK, Tecoma ES, et al. Vagus nerve stimulation therapy for partial-onset seizures: a randomized active-control trial. Neurology. 1998;51(1):48-55.

15. Bernstein AL, Barkan H, Hess T. Vagus nerve stimulation therapy for pharmacoresistant epilepsy: effect on health care utilization. Epilepsy Behav. 2007;10(1):134-7.

16. Helmers SL, Duh MS, Guérin A, Sarda SP, Samuelson TM, Bunker MT, et al. Clinical and economic impact of vagus nerve stimulation therapy in 
patients with drug-resistant epilepsy. Epilepsy Behav. 2011;22(2):370-5.

17. United States Census. Population by age and sex;2012. https://www.census.gov/data/tables/ 2012/demo/age-and-sex/2012-age-sexcomposition.html. Accessed 15 Sep 2017.

18. Centers for Disease Control and Prevention. Epilepsy fast facts;2016. https://www.cdc.gov/epilepsy/ basics/fast-facts.htm. Accessed 9 Jan 2017.

19. Hauser WA, Annegers JF, Kurland LT. Incidence of epilepsy and unprovoked seizures in Rochester, Minnesota: 1935-1984. Epilepsia. 1993;34(3):453-8.

20. Kwan P, Arzimanoglou A, Berg AT, Brodie MJ, Allen Hauser W, Mathern G, et al. Definition of drug resistant epilepsy: consensus proposal by the ad hoc Task Force of the ILAE Commission on Therapeutic Strategies. Epilepsia. 2010;51(6):1069-77.

21. Medical Services Advisory Committee (MSAC). Australian Government Public Summary Document, Application No. 1358.1 Vagus Nerve Stimulation (VNS) Therapy (resubmission). 2016. http:// www.msac.gov.au/internet/msac/publishing.nsf/ Content/1358.1-public. Accessed 21 Mar 2016.

22. Messori A, Trippoli S, Becagli P, Cincotta M, Labbate MG, Zaccara G. Adjunctive lamotrigine therapy in patients with refractory seizures: a lifetime cost-utility analysis. Eur J Clin Pharmacol. 1998;53(6):421-7.

23. Ryvlin P, Gilliam FG, Nguyen DK, Colicchio G, Iudice A, Tinuper $P$, et al. The long-term effect of vagus nerve stimulation on quality of life in patients with pharmacoresistant focal epilepsy: the PuLsE (Open Prospective Randomized Long-term Effectiveness) trial. Epilepsia. 2014;55(6):893-900.

24. Sullivan SD, Mauskopf JA, Augustovski F, Caro JJ, Lee KM, Minchin M, et al. Budget impact analysisprinciples of good practice: report of the ISPOR 2012 Budget Impact Analysis Good Practice II Task Force. Value Health. 2014;17(1):5-14.

25. Boon $\mathrm{P}$, Vonck $\mathrm{K}$, Vandekerckhove $\mathrm{T}, \mathrm{D}^{\prime}$ have $\mathrm{M}$, Nieuwenhuis L, Michielsen G, et al. Vagus nerve stimulation for medically refractory epilepsy; efficacy and cost-benefit analysis. Acta Neurochir (Wien). 1999;141(5):447-53.

26. Chen Z, Brodie MJ, Liew D, Kwan P. Treatment outcomes in patients with newly diagnosed epilepsy treated with established and new antiepileptic drugs: a 30-year longitudinal cohort study. JAMA Neurol. 2018;75(3):279-86.
27. Elliott RE, Morsi A, Kalhorn SP, Marcus J, Sellin J, Kang M. et al Vagus nerve stimulation in 436 consecutive patients with treatment-resistant epilepsy: long-term outcomes and predictors of response. Epilepsy Behav. 2011;20(1):57.

28. Ben-Menachem E, Hellström K, Waldton C, Augustinsson LE. Evaluation of refractory epilepsy treated with vagus nerve stimulation for up to 5 years. Neurology. 1999;52(6):1265-7.

29. Elliott RE, Rodgers SD, Bassani L, Morsi A, Geller EB, Carlson $\mathrm{C}$, et al. Vagus nerve stimulation for children with treatment-resistant epilepsy: a consecutive series of 141 cases. J Neurosurg: Pediatr. 2011;7(5):491-500.

30. Helmers SL, Duh MS, Guérin A, Sarda SP, Samuelson TM, Bunker MT, et al. Clinical outcomes, quality of life, and costs associated with implantation of vagus nerve stimulation therapy in pediatric patients with drug-resistant epilepsy. Eur J Paediatr Neurol. 2012;16(5):449-58.

31. Forbes R. Cost-utility of vagus nerve stimulation (VNS) therapy for medically refractory epilepsy-an update. Seizure. 2008;17(4):387-8.

32. Red Book Online. http://www.micromedexsolutions. com/. Accessed 20 Nov 2016.

33. HCUPnet. Agency for Healthcare Research and Quality. National statistics on all hospital stays;2014. https://hcupnet-archive.ahrq.gov/. Accessed 17 Nov 2017.

34. United States Department of Labor. Bureau of Labor Statistics. Medical Care Services: Consumer Price Index; 2016.

35. Centers for Disease Control and Prevention. Health, United States, 2012: with special feature on emergency care;2012. https://www.cdc.gov/nchs/data/ hus/hus12.pdf. Accessed 3 Apr 2018.

36. Kristian B, Wachtmeister K, Stefan F, Forsgren L. Retigabine as add-on treatment of refractory epilepsy-a cost-utility study in a Swedish setting. Acta Neurol Scand. 2013;127(6):419-26.

37. Purser M, Mladsi D, Beckman A, Barion F, Forsey J. Expected budget impact of expanded use of VNS Therapy. American Epilepsy Society 2017 Annual Meeting Abstract Database. Abstract 1.385. https:// www.aesnet.org/meetings_events/annual_meeting_ abstracts/view/337250. 